\title{
CRYSTALLOGRAPHIC TEXTURE IN PULSE CURRENT ELECTROFORMING OF NICKEL
}

\author{
K.C. CHAN ${ }^{\mathrm{a}, *}$, N.S. QU ${ }^{\mathrm{a}}$ and D. ZHU ${ }^{\mathrm{b}}$ \\ a Department of Manufacturing Engineering, The Hong Kong Polytechnic \\ University, Hong Kong, ' Department of Mechanical Engineering, Nanjing \\ University of Aeronautics and Astronautics, Nanjing, P.R. China
}

(Received 12 December 1996; 12 March 1997)

Nickel deposits are rather seldom randomly oriented; they usually exhibit a column-like orientation with a definite $[\mathrm{hkl}]$ axis along the electric field direction in the electroforming process. However, up to present, most of the studies in electroforming nickels are still using a nickel sulfate bath which is now not commonly used in precise-electroforming or micro-electroforming. In this paper, an experimental investigation on the effect of pulse current on texture in micro-electroforming nickel has been carried out using a nickel sulphamate bath. It was reported that strong and weak [100] texture were formed at different pulse current conditions. These phenomena were considered to be related to the change of the amount of inhibiting chemical species at different conditions.

Keywords: Electroforming of nickel; Pulse current; Texture; Inhibiting chemical species

\section{INTRODUCTION}

Crystallographic texture which is related to the mechanical and physical properties of a metal is an important microstructural feature of metallic deposits. In order to allow deposits with defined magnetic properties, there has been a considerable interest in the past decade to study crystallographic texture in electrodeposition processes (Kollia et al., 1990; 1991; Kollia and Spyrellis, 1990; 1991; 1994; Abel et al., 1994). It has been reported that a fiber texture is commonly observed in

\footnotetext{
${ }^{*}$ Corresponding author.
} 
a metallic deposit, and that the texture depends on electrolysis conditions and electrolyte compositions (Amblard et al. 1984; Paatsch, 1988). Among these studies, much attention has been paid on electrodeposition of nickel using a nickel sulfate bath (Amblard et al., 1977; 1979; 1986; Ibl et al., 1978; Ibl, 1980; Tescheke and Soares, 1984; Kollia et al., 1990; Kollia and Spyrellis, 1990; 1991; 1994; Kollia et al., 1991) which is commonly used in electroplating. With direct current, different textures are observed in the deposits under different conditions (Amblard et al., 1984; Kollia et al., 1990). In pulse current electrodeposition, there are three independent variables: the peak current density, $i_{\mathrm{p}}$, the deposition time, $T_{\text {on }}$ and the off-period, $T_{\text {off }}$. By varying these parameters, a variety of mass transport situations, a variety of adsorption and desorption phenomena during both the deposition time and the off-time and a variety of electrocrystallization conditions can be obtained. It has been reported that the desorption phenomenon occurring during the relaxation time is shown to be related to the texture formation and the modification of structures and properties of the deposits (Ibl et al., 1978; Ibl, 1980; Amblard et al., 1986; Kollia et al., 1991).

Although there have been a lot of studies to investigate crystallographic texture in electroforming using a nickel sulfate bath, research in micro-electroforming using a nickel sulphamate bath is less reported. The present paper is hence to investigate for the first time the effect of pulse current on texture in nickel deposits in micro-electroforming and to compare these findings with those obtained using direct current.

\section{EXPERIMENTAL}

The bath composition is nickel sulphamate $330 \mathrm{~g} / \mathrm{l}$; nickel choride $15 \mathrm{~g} / \mathrm{l}$; boric acid $40 \mathrm{~g} / \mathrm{l}$; sodium dodecyl sulphate $0.2 \mathrm{~g} / 1$. In the electrodeposition process, the electrolyte was agitated, and the temperature was kept at $50 \pm 2^{\circ} \mathrm{C}$. The initial pH of the electrolyte was fixed at 4.8, a typical $\mathrm{pH}$ value used in electroforming. Figure 1 presents a schematic diagram of the experimental set-up. The waveform of a pulse current is shown in Fig. 2, and is defined by the peak current density, $i_{\mathrm{p}}$, the frequency, $f$, and the duty cycle $T_{\text {on }} /\left(T_{\text {off }}+T_{\text {on }}\right)$.

In direct current electroforming, the current density varied from 1.2 to $8 \mathrm{~A} \mathrm{dm}^{-2}$. In pulse current electroforming, $i_{\mathrm{p}}, T_{\text {on }}$ and $T_{\text {off }}$ were 


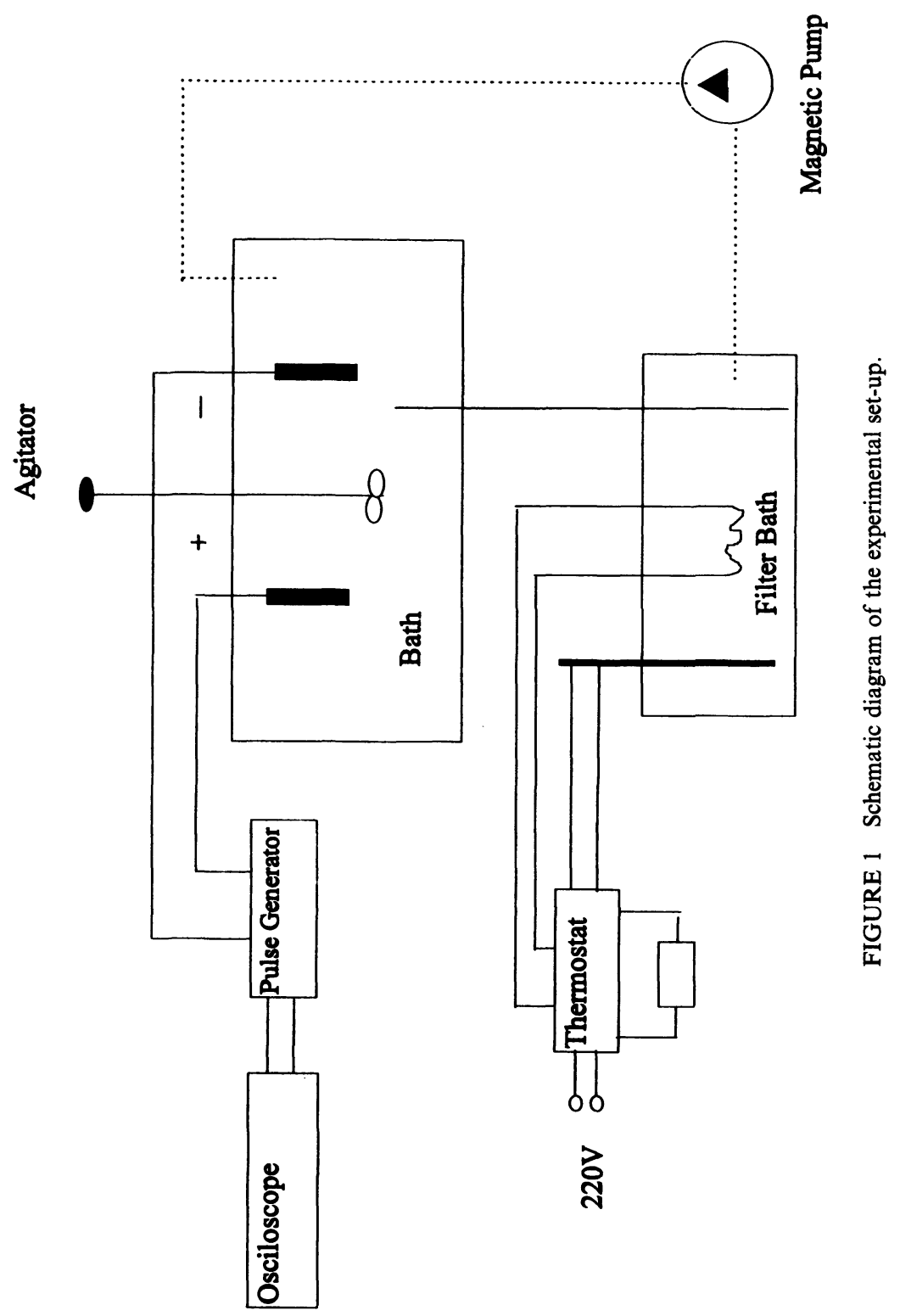




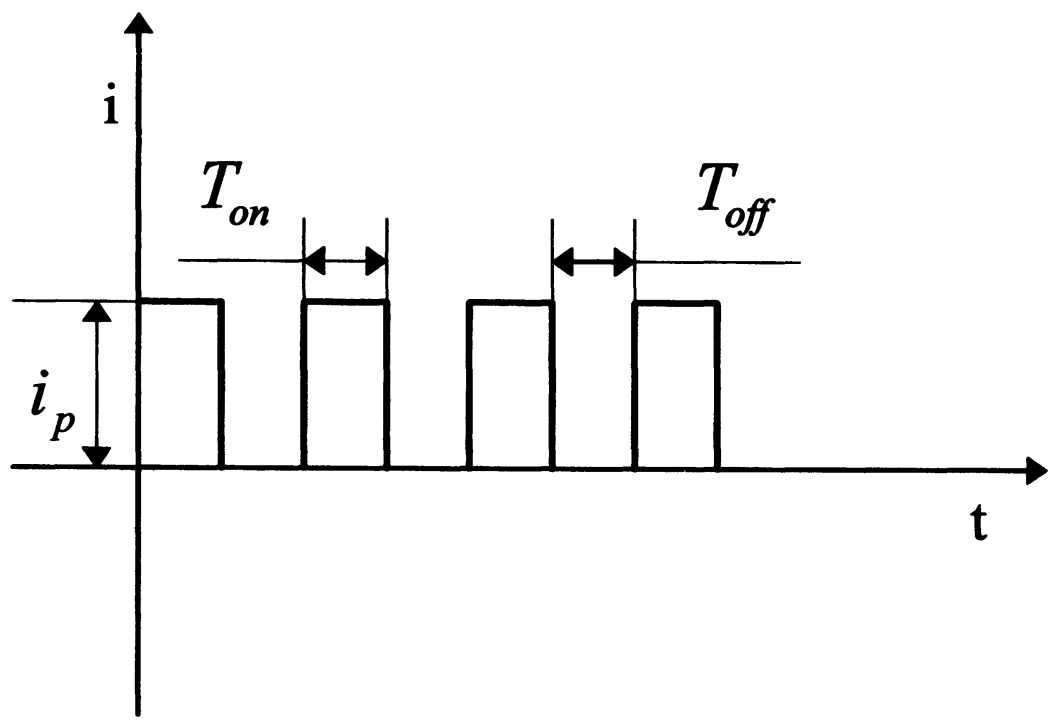

FIGURE 2 Waveform of a pulse current.

varied. $T_{\text {on }}$ and $T_{\text {off }}$ are shown to be important in pulse current electroforming because they are related to the adsorption-desorption phenomena occurring on the metallic surface. In the experiments, $T_{\text {on }}$ was varied from 2 to $20 \mathrm{~ms}$ at a peak current density of $16 \mathrm{~A} \mathrm{dm}^{-2}$ and an off-time of $10 \mathrm{~ms}, T_{\text {off }}$ was varied from 2 to $40 \mathrm{~ms}$ at a peak current density of $16 \mathrm{~A} \mathrm{dm}^{-2}$ and an on-time of $10 \mathrm{~ms}$, and $i_{\mathrm{p}}$ was varied from 10 to $24 \mathrm{~A} \mathrm{dm}^{-2}$ at an on-time and an off-time of $10 \mathrm{~ms}$. The mandrel which nickel will deposit onto was a mechanically polished steel plate. In order to produce deposit layers of minimum thickness of $50 \mu \mathrm{m}$, the total deposition time was varied from 1 to $4 \mathrm{~h}$. The textures of nickel deposits were measured by a Philips X-ray diffractometer. Three incomplete pole figures: $\{200\},\{110\}$ and $\{211\}$ (with $0<\psi<70^{\circ}$, $0<\phi<90^{\circ}$ ) were obtained by the back reflection method at $5^{\circ}$ increments using $\mathrm{Cu} \mathrm{K} \alpha$ radiation. From the pole figures, ODFs were calculated by the software developed by Cai and Lee (1995) using the series expansion method. The series were truncated at $l_{\max }=16$. Inverse pole figures for the sample normal direction were then obtained from the ODFs. 


\section{RESULTS AND DISCUSSIONS}

The effect of current density on texture in direct current electroforming is shown in Fig. 3(a), (b). Both the textures of the nickel deposits at a current density of 1.2 and $8 \mathrm{~A} \mathrm{dm}^{-2}$ are observed to be quite randomly oriented. The electrocrystallization of nickel is known to be a highly inhibited process (Amblard et al., 1979; Kollia et al., 1991; Kotzia et al., 1991). Both the chemical species which include atomic hydrogen, molecular hydrogen and nickel hydroxide absorbed on the deposition surface and the organic additives in close proximity to the surface will inhibit crystal growth and determine the texture. After certain

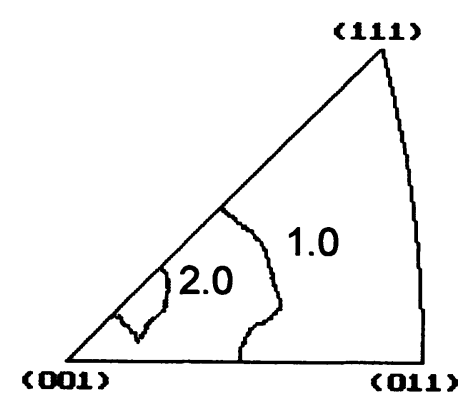

(a)

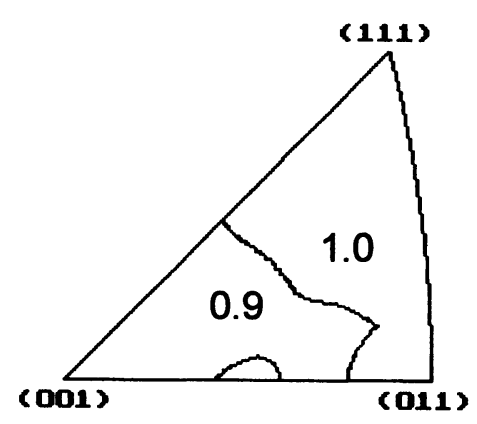

(b)

FIGURE 3 The inverse pole figure of nickel deposits at different current densities: (a) current density of $1.2 \mathrm{~A} \mathrm{dm}^{-2}$; (b) current density of $8 \mathrm{~A} \mathrm{dm}^{-2}$. 
deposition time, significant amount of chemical species are formed and absorbed on the deposition surface. It will then come up to a dynamic equilibrium, that is to say, significant amount of inhibiting chemical species absorbed on the mandrel surface will then be kept constant on the whole electroforming process. The presence of this significant amount of chemical species on the deposition surface greatly affects the texture formation. On the other hand, since organic additives are consumed in the process of electroforming, the amount of additives in close proximity to the deposition surface will become very little after certain deposition time, which will have little effect on crystal growth. As a result of the inhibiting effect of chemical species, a random texture is obtained for the current density being 1.2 and $8 \mathrm{~A} \mathrm{dm}^{-2}$ in direct current electroforming.

In pulse current electroforming, the effect of off-time on texture formation at an on-time of $10 \mathrm{~ms}$ and a peak current density of $16 \mathrm{~A} \mathrm{dm}^{-2}$ is shown in Fig. 4(a)-(c). Figure 4(a) shows that the texture of the nickel deposits at an off-time of $2 \mathrm{~ms}$ is a weak [100] texture. Whereas a strong [100] texture is shown in Fig. 4(b) and (c) for the offtime being 10 and $30 \mathrm{~ms}$. The change of the density of the [100] texture may be attributed to the change of the amount of inhibiting chemical species at different off-times. Organic additives are believed to play no significant role in this phenomenon as most of them in close proximity to the deposition surface are consumed at the on-time of $10 \mathrm{~ms}$. When

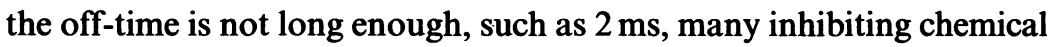
species, which are adsorbed on the deposition surface, will not desorb wholly from the deposition surface during the off-time. The crystal growth is therefore extremely inhibited by chemical species already adsorbed on the deposition surface. Consequently, only a weak [100] texture is obtained. In contrast, when off-time is long enough such as $10 \mathrm{~ms}$, chemical species are desorbed from the deposition surface during the off-time, and the electrocrystallization process occurs nearly in a condition free from inhibiting chemical species. Therefore, a strong [100] texture is obtained.

The effect of on-time on texture at an off-time of $10 \mathrm{~ms}$ and a peak current density of $16 \mathrm{~A} \mathrm{dm}^{-2}$ is shown in Figs. 4(b) and 5(a), (b). Figure 5 (a) shows that texture of nickel deposits at an on-time of $2 \mathrm{~ms}$ is a weak [100] texture. Whereas a strong [100] texture is shown in Figs. 4(b) and 5(b) for the on-time being 10 and $20 \mathrm{~ms}$. As discussed previously, 


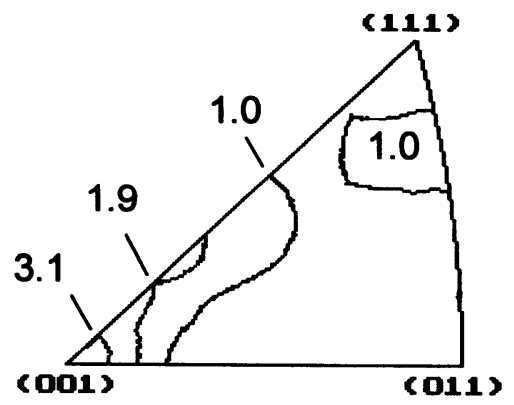

(a)

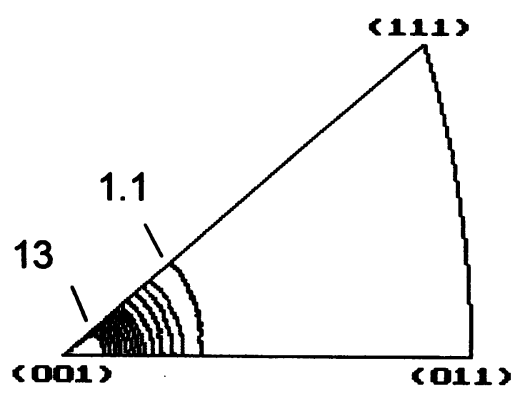

(b)

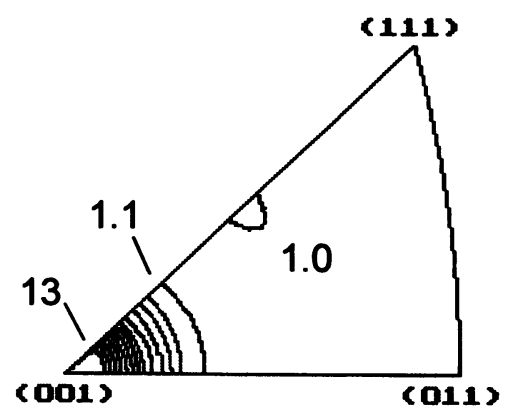

(c)

FIGURE 4 The inverse pole figure of nickel deposits at an on-time of $10 \mathrm{~ms}$, a peak current density of $16 \mathrm{~A} \mathrm{dm}^{-2}$ and different off-times: (a) at an off-time of $2 \mathrm{~ms}$; (b) at an off-time of $10 \mathrm{~ms}$; (c) at an off-time of $30 \mathrm{~ms}$. 
chemical species already adsorbed on the mandrel surface will desorb from the surface during a relatively long off-time of $10 \mathrm{~ms}$, which resulted in a strong [100] texture as shown in Figs. 4 (b) and 5(b) when the on-time is 10 and $20 \mathrm{~ms}$. At these on-times, organic additives are shown to play little effect on the texture formation as most of them in close proximity to the deposition surface are consumed. However, at an on-time of $2 \mathrm{~ms}$, only small amount of organic additives is consumed. The presence of the additives hence inhibits the crystal growth and provokes the formation of a weak [100] texture as shown in Fig. 5(a).

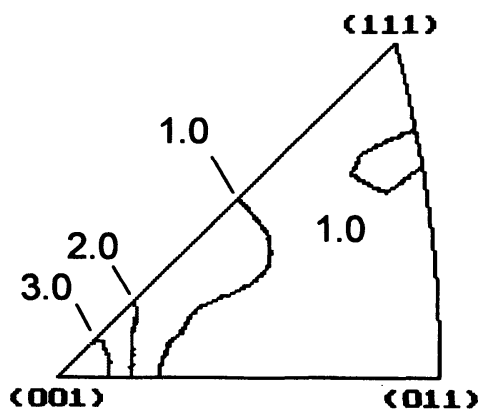

(a)

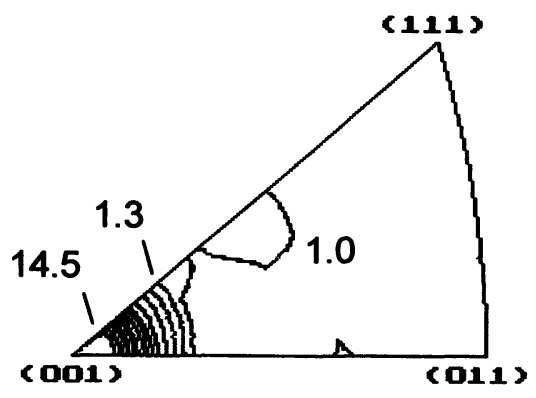

(b)

FIGURE 5 The inverse pole figure of nickel deposits at an off-time of $10 \mathrm{~ms}$, a peak current density of $16 \mathrm{~A} \mathrm{dm}^{-2}$ and different on-times: (a) at an on-time of $2 \mathrm{~ms}$; (b) at an on-time of $20 \mathrm{~ms}$. 
The effect of current density on texture at an off-time and an on-time of $10 \mathrm{~ms}$ is shown in Figs. 4(b) and 6(a), (b). Figure 6(a) shows that the texture of the nickel deposit at a peak current density of $10 \mathrm{~A} \mathrm{dm}^{-2}$ is a strong texture of [100]. A strong texture of [100] is also observed as shown in Fig. 4(b) when the peak current density is $16 \mathrm{~A} \mathrm{dm}^{-2}$. However a weak texture of [100] is shown in Fig. 6(b) at a peak current density of $24 \mathrm{~A} \mathrm{dm}^{-2}$. The higher the peak current density in electrodeposition, the more is the amount of chemical species absorbed at the deposit. When a peak current is high enough, such as $24 \mathrm{~A} \mathrm{dm}^{-2}$, significant amount of chemical species absorbed on the deposition surface will inhibit the growth of the crystallites. [100] orientation is therefore

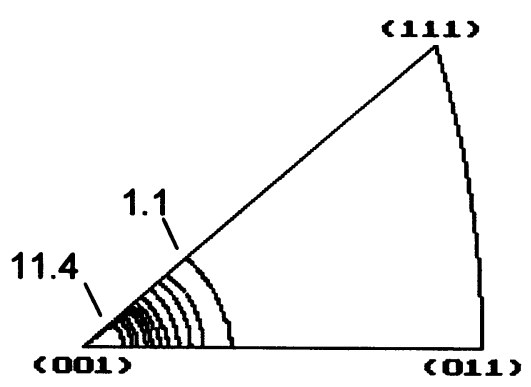

(a)

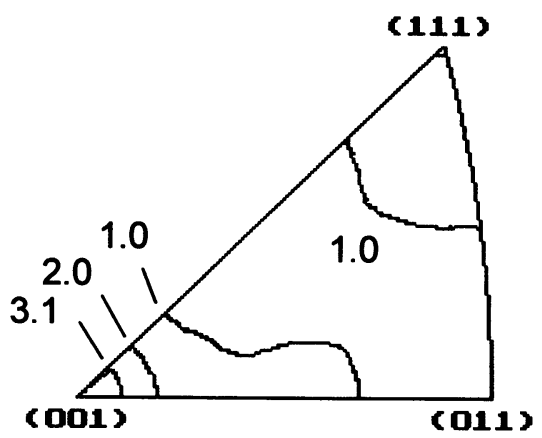

(b)

FIGURE 6 The inverse pole figure of nickel deposits at an on-time of $10 \mathrm{~ms}$, an offtime of $10 \mathrm{~ms}$ and different peak current density: (a) at a peak current density of $10 \mathrm{~A} \mathrm{dm}^{-2}$; (b) at a peak current density of $24 \mathrm{Adm}^{-2}$. 
difficult to form. In contrast, when a peak current density, such as $16 \mathrm{~A} \mathrm{dm}^{-2}$, is not high enough, less amount of inhibitors will be produced and the crystal growth is therefore nearly free from inhibitors.

The above findings are significant in better understanding the basic phenomenon in texture formation in electroforming though more experimental and theoretical works have to be done. The findings of this paper are also important in producing magnetic microactuators which are now commonly produced by micro-electroforming requiring defined magnetic properties. These properties are related to the texture. Depending on the applications, strong or weak magnetic properties can be produced through the control of texture by varying the pulse parameters in pulse current electroforming.

\section{CONCLUSIONS}

In this paper, an experimental investigation on the effect of both direct current and pulse current on texture in micro-electroforming nickel has been carried out for the first time. According to the experimental findings, strong and weak [100] texture can be obtained at different pulse current conditions, and a random texture was formed in direct current. The formation of strong and weak [100] texture can be explained by the change of chemical species and organic additives at different conditions. The findings are of significance in better understanding the deposit quality in micro-electroforming and in forming a basis for further studies in this area.

\section{Acknowledgement}

Financial support for the code No. 454/044 from the Hong Kong Polytechnic University is acknowledged.

\section{References}

Abel, S., Freimuth, H., Lehr, H. and Mensiger, H. (1994). Defined crystal orientation of nickel by controlled microelectroplating. J. of Micromech. Microengg., 4, 47-54.

Amblard, J., Froment, M., Maurin, G. and Spyrellis, N. (1977). Origine des textures dans les dépôts électrolytiques de nickel. Surf. Technol., 5, 205-244.

Amblard, J., Epelboin, I., Froment, M. and Maurin, G. (1979). Inhibition and nickel electrocrystallization. J. Appl. Electrochem., 9, 244-242. 
Amblard, J., Froment, M., Maurin, G., Spyrellis, N. and Trevisansouteyrand, E. (1984). Nickel electrocrystallisation - from nucleation to textures. Electrochim. Acta, 28, 909-915.

Amblard, J., Froment, M., Maurin, G. and Spyrellis, N. (1986). Pulse plating - a perturbation probe into nickel electrocrystallization. Electrochemical Soc., 144, C700C701.

Cai, M.J. and Lee, W.B. (1995) The development of a computer software system for the prediction of formability parameters of sheet metals from X-ray diffraction data. Journal of Materials Processing Technology, 48, 51-57.

Kollia, C. and Spyrellis, N. (1990). Modification of Microstructure and properties in nickel electrodeposits by using reversed current. Proc. of the first European Conference - Advanced Materials and Processes, Eds., H.E. Exner and V. Schumacher, Vol. 2, DGM, Oberursel, Germany, 1149-1144.

Kollia, C., Spyrellis, N., Amblard, J., Epelboin, I., Froment, M. and Maurin, G. (1990). Nickel plating by pulse electrolysis: textural and microstructural modifications due to adsorption/desorption phenomena. J. Appl. Electrochem., 20, 1025-1042.

Kollia, C., Loizos, Z. and Spyrellis, N. (1991). Influence of pulse reversed current technique on the crystalline orientation and surface morphology of nickel electrodeposits. Surf. Coat. Technol., 45, 155-160.

Kollia, C. and Spyrellis, N. (1991). Nickel electrodeposition by pulsed reversed current in the presence of organic additives. Proc. 2nd. Eur. Conf. on Advanced Materials and Processes, Cambridge, London, 71-75.

Kollia, C. and Spyrellis, N. (1994). Textural modifications and nickel electrodeposition under pulse reversed current. Surf. Coat. Technol., 57, 71-75.

Kotzia, F., Kollia, C. and Spyrellis, N. (1991). Nickel electrodeposition by pulsed reversed current in the presence of organic additives. Proc. Eur. Conf. on Advanced Materials Processes 2nd Meeting, Vol. 1, Eds., T.W. Clyne and P.J. Withers (London: Institute of Materials) pp. 229-244

Ibl, N., Puipe, J.C. and Angerer, H. (1978). Electrocrystallization in pulse electrolysis. Surf. Technol., 6, 287-400.

Ibl, N. (1980). Some theoretical aspects of pulse electrolysis. Surf. Technol. 10, 81-85.

Paatsch, W. (1988). Morphology and permeability of nickel electrodeposits. Plating Surf. Finishing, 75, 52-55.

Teschke, O. and Soares, D.M. (1984). Electrodeposition of nickel by an asymmetric periodically reverse step current. J. Electrochem. Soc., 140, 406-410. 